\title{
Soft Computing Based Fault Diagnosis
}

\author{
K. Vinoth Kumar, Member, IEEE, S. Suresh Kumar, Member, IEEE and Badugu Praveena
}

\begin{abstract}
Induction machines play a pivotal role in industry and there is a strong demand for their reliable and safe operation. They are generally reliable but eventually do wear out. Faults and failures of induction machines can lead to excessive downtimes and generate large losses in terms of maintenance and lost revenues, and this motivates the examination of on-line condition monitoring. On-line condition monitoring involves taking measurements on a machine while it is operating in order to detect faults with the aim of reducing both unexpected failures and maintenance costs. Thus the key for the success of condition based maintenance is having an accurate means of condition assessment and fault diagnosis. The stator is subjected to various stresses such as thermal, electrical, mechanical, and environmental, which severely affects the stator condition leading to faults. These stresses can be classified into phase-to-phase, turn-to-turn, and turn-to-ground. The fault detection using analytical methods is not always possible because it requires a perfect knowledge of the motor model. The fuzzy logic techniques are rather easy to develop and to perform.A Simulink model are developed in Matlab/SIMULINK for Induction Motor using Fuzzy-logic Controller to analyze the performance under the turn-turn short in one phase winding, open phase faults.
\end{abstract}

Index Terms - Induction Motor, Condition Monitoring, Stator monitoring, Fuzzy Logic, Matlab/SIMULINK, Fault Detection.

\section{INTRODUCTION}

Three-phase induction motors are the "workhorses" of industry and are the most widely used electrical machine. Because of its simple structure and high reliability, induction motor is used for many purposes such as: pumps, blowers, fans, compressors, transportation, etc. In an industrialized nation, they can consume between 40 to $50 \%$ of total generated capacity of that country [1]. However, owing to the thermal, electrical and mechanical stresses, mechanical and electrical failures are unavoidable in induction motors. Early detection of abnormalities in the motor will help to avoid expensive failures. Operators of electric drive systems are under continual pressure to reduce maintenance costs and prevent unscheduled downtimes that result in lost production and loss of financial income. The modern industry has widely used reliability-based and condition-based maintenance

Manuscript received January 21, 2010.

K. Vinoth Kumar, is with Department of Electrical and Electronics Engineering, Karunya University, Coimbatore-641114, India.

(E-mail: kvinoth_kumar84@yahoo.in).

Dr. S. SureshKumar, is with Department of Electrical and Electronics Engineering, Karunya University, Coimbatore-641114, India.

(E-mail: ssk@karunya.edu).

Badugu Praveena, is with Department of Electrical and Electronics Engineering, Karunya University, Coimbatore-641114, India.

(E-mail: mtch_praveena@yahoo.com). strategies to reduce unexpected failures and downtime. These techniques can increase the time between planned shutdowns for standard maintenance and reduce maintenance and operational costs. The operation of the machine in unsafe condition must also be avoided. Nevertheless, the failures are unavoidable, and failure statistics has reported that the percentage of failures in induction motor components is as follows:

1) Bearing related faults: $40 \%$

2) Stator winding related faults: $38 \%$

3) Rotor related faults: $10 \%$

4) Other faults: $12 \%$

It is important to note that even if the stator fault account makes up $38 \%$ of the all faults, it is very important to spot them in time because they can lead to the total destruction of the motor. A reliable system for the detection of such a fault should be able to detect the fault at an early stage, monitoring the motor condition online.

\section{Various Stator Faults And CaUSES/Stresses LEADING TO THESE FAULTS}

The stator is subjected to various stresses such as thermal, electrical, mechanical, and environmental, which severely affects the stator condition leading to faults. The stator defects/faults can be broadly classified into the following two categories.

1) Laminations (Core hot spot, Core Slackening), frame (Vibration, Circulating currents, loss of coolants, earth faults).

2) Stator windings Defects/Faults: The most common defects/faults of stator windings are related to either the "end winding portion" or the "slot portion" as given below:

a) End-winding portion(local damage to insulation, cracking of insulation, turn-to-turn faults, discharge erosion of insulation)

b) Slot portion(fretting of insulation, displacement of conductors)

The various causes of stator failures have been identified. The majority of these faults are caused because of a combination of various stresses acting on the stator, which can be classified into thermal, electrical, mechanical, and environmental. [2]

\section{A. Thermal Stresses:}

These stresses might be due to thermal aging and thermal overloading. As a thumb rule, for every $10^{\circ} \mathrm{C}$ increase in temperature, the insulation life gets halved due to thermal aging. The effect of temperature on thermal aging can be minimized by using any of two approaches to ensure longer thermal life: either by reducing the operating temperature or 
by increasing the class of insulation materials used. Thermal overloading can occur due to the applied voltage variations, unbalanced phase voltage, cycling overloading, obstructed ventilation, higher ambient temperature, etc. As a thumb rule, for every $3.5 \%$ voltage unbalance per phase, the winding temperature increases by $25 \%$ in the phase with the highest current.

\section{B. Electrical Stresses:}

The electrical stresses leading to winding failures can be classified into dielectric, tracking, corona, and transient voltage conditions. The definite relationship between insulation life and the voltage stresses applied to the insulating materials has to be taken into consideration while selecting the materials and establishing the coil designs for adequate design life. These stresses can be classified into phase-to-phase, turn-to-turn, and turn-to-ground. If the insulation system is not completely protected from the environment, then in the motors with operating voltages over $600 \mathrm{~V}$, a phenomenon known as tracking occurs in the windings leading to ground failures. Transient voltage conditions result in reduced winding life or premature failure (either turn-to-turn or turn-to-ground). These conditions can be caused by line-to-line, line-to-ground, multiphase line-to-ground, and three-phase faults, repetitive restriking, current-limiting fuses, rapid bus transfers, opening and closing of circuit breakers, capacitor switching, insulation failure, lightning, and variable frequency drives.

\section{Mechanical Stresses:}

These stresses might be due to coil movement and rotor striking the stator. The rotor can strike the stator due to a number of reasons like bearing failures, shaft deflection, rotor-to-stator misalignment, etc. If the strike happens only during startup, then the force of the rotor can cause the stator laminations to puncture the coil insulation, resulting in grounding the coil. If the rotor strikes the stator when the motor is running at full speed, then the result is very premature grounding of the coil in the stator slot caused by excessive heat generated at the point of contact. There might be many other causes for winding failures like rotor balancing weights coming loose and striking the stator, rotor fan blades coming loose and striking the stator, foreign particles/bodies entering the motor through the ventilation system and striking the stator, a defective rotor (e.g., open rotor bars) causing the stator to overheat and fail, and broken lamination teeth striking the stator due to fatigue. A part of broken bars may work itself into the air gap, causing immediate failure to copper-iron.[3]

\section{Environmental Stresses/Contamination:}

The presence of foreign material could cause various ill effects on the functioning of the motor-like reduction in heat dissipation (which will increase operating temperature thereby reducing insulation life), premature bearing failure due to high-localized stresses, and breakdown of the insulation system (causing shorts and grounds). Every step should be taken to restrict/ minimize the moisture, chemicals, and foreign particles from interacting with the motor surface.

\section{CONDITION MOnitoring On Induction Motor}

Condition monitoring is an important issue in many fields, including railways, power delivery, and electrical machines and motors. Condition monitoring can be defined as a technique or process of monitoring the operating characteristics of a machine so that changes and trends of the monitored signal can be used to predict the need for maintenance before a breakdown or serious deterioration occurs, or to estimate the current condition of the machine. Considering an Example for Induction Motor Bearing Damage, it can be seen that Induction motors are a widely studied subject in condition monitoring. There are several different methods for recognizing failures. The most widely studied methods in bearing Condition monitoring is based on measurements of vibration, acoustic noise, or temperature. Vibration- and stator-current based methods seem to be some of the most popular. When monitoring bearing damage in induction motors, the characteristic frequencies of bearing damage are often used to monitor certain frequency components in either vibration or stator current signals.

\section{A. Benefits Of Condition Monitoring}

Plant machineries are invaluable assets and are designed to operate under extremely harsh condition, where a failure may be catastrophic, both in safety and economic aspects.

1) Vibration Problem identification of rotating machines.

2) Exploring the cause of repetitive failure of machines

3) Ensuring the safety of the equipment against Vibration \& Shock.

4) Dynamic balancing of Rotors and rotating components

5) Measurement of Natural frequency in static condition

6) Less downtime \& more productivity

7) Reduced inventory for spares.

8) Enhancing the machine endurance limit

9) Greater safety to work force.

\section{B. Monitoring Techniques}

These monitoring techniques have been classified into the

following eight categories using different parameters is mentioned below.

1) Magnetic Flux

Any distortion in the air-gap flux density due to stator defects will set up an axial homopolar flux in the shaft, which can be sensed by a search coil fitted around the shaft. By using a minimum of four search coils located asymmetrically to the drive shaft, the location of shorted turn can be found out.[4]

\section{2) Vibration}

The stator frame vibration is a function of inter turn winding faults, single phasing, and supply-voltage unbalance. The resonance between the exciting electromagnetic (EM) force and the stator is one of the main causes of noise production in electrical machines.

\section{3) Current}

The current drawn by an ideal motor will have a single component at the supply. The motor current signature analysis (MCSA) utilizes the results of the spectral analysis 
of the stator current of an induction motor to pinpoint an existing or incipient failure of the motor or the driven system. The diagnostic analysis has been reported by various researchers using the sequence components of current, radio-frequency ( $\mathrm{RF}$ ) component of neutral current, and shaft currents.

\section{4) Induced Voltage}

The voltage induced along the shaft of a machine (generator) is an indication of the stator core or winding degradation. Shaft voltage has not yet proved to be a useful parameter for continuous monitoring because it is difficult to measure in a reliable way. The maximum turn-fault sensitivity is obtained after band pass filtering around the fundamental frequency.

\section{5) Power}

The instantaneous electric power has definite advantages in comparison to current as a detection parameter. The characteristic spectral component of the power appears directly at the frequency of the disturbance, independent of the synchronous speed of the motor. The utilization of the instantaneous power enhances the reliability of the diagnostics of the induction motors.

\section{6) Surge Testing}

The surge testing is an established method for diagnosing winding faults. In the surge comparison test, two identical high voltages, high-frequency pulses are simultaneously imposed on two phases of the motor winding with third phase grounded. An oscilloscope is used to compare the reflected pulses indicating the insulation faults between windings, coils, and group of coils.

\section{7) Motor Circuit Analysis}

By measuring the EM properties of the electric motor as an electric circuit, the motor circuit analysis (MCA) determines the variations within the motor and identifies the defects. In MCA, a low amount of energy with amplified responses is applied. The responses help in evaluating the condition of both the windings and rotor through the comparative readings.

\section{8) AI-based fault monitoring approaches}

Despite the various techniques mentioned in the section, the monitoring and fault detection of electrical machines have moved from the traditional techniques to AI techniques in recent years. The main steps of an AI-based diagnostic mechanism are signature extraction, fault identification, and fault severity evaluation. The various AI techniques, expert systems, artificial neural networks (ANNs), fuzzy logic, fuzzy neural networks (NNs), genetic algorithms, etc. for the fault diagnostics of stator faults have been reported in the literature.

\section{Stator Current Monitoring System}

A stator current signal contains potential fault information. The most suitable measurements for diagnosing the faults under consideration, in term of easy accessibility, reliability, and sensitivity, are the stator current amplitudes $\mathrm{I}_{\mathrm{a}}, \mathrm{I}_{\mathrm{b}}$, and $\mathrm{I}_{\mathrm{c}}$, These amplitudes are monitored by the system illustrated by Fig.1. On-line condition monitoring uses measurements taken while a machine is operating to determine if a fault exists. Starting from the left, common motor faults are shown. Different types of sensors can be used to measure signals to detect these faults. Various signal processing techniques can be applied to these sensor signals to extract particular features which are sensitive to the presence of faults.[5]

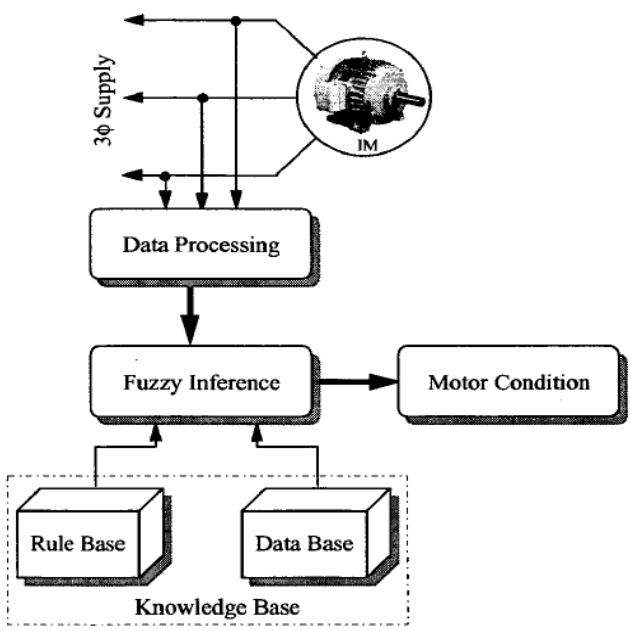

Fig 1. Block Diagram of Induction Motor Condition Monitoring System

\section{FuZzy Logic Approach For The Fault Diagnosis IN INDUCTION MOTOR}

In the motor fault diagnosis process, time domain current signals are captured from sensors. The diagnostic expert then uses both time domain and frequency domain signals to study the motor condition and determines what faults are present. However, experienced engineers are often required to interpret measurement data that are frequently inconclusive. A fuzzy logic approach may help to diagnose induction motor faults. Fuzzy logic is reminiscent of human thinking process and natural language enabling decisions to be made based on vague information.

Fuzzy logic allows items to be described as having a certain membership degree in a set. While conducting fault diagnosis, there are several situations in which an object is not obviously "Good" or "Damaged", but may fall into some interior range. According to the fact that induction motor condition interpretation is a fuzzy concept, here the motor condition is described using linguistic variables. Fuzzy subsets and the corresponding membership functions describe stator current amplitudes. A knowledge base, comprising rule base is built to support the fuzzy inference. The induction motor condition is diagnosed using a compositional rule of fuzzy inference. The obtained results indicate that the proposed fuzzy logic approach is capable of highly accurate diagnosis. The stator current signal contains the information about faults in the motor. Fuzzy systems rely on a set of rules. These rules, allow the input to be fuzzy, i.e. like an electrical machine referred as "somewhat secure", "little overloaded". This linguistic input can be expressed directly by a fuzzy system.

$$
\begin{aligned}
& \mathrm{I}_{\mathrm{a}}=\{\omega \alpha(\bar{\omega} \alpha j) \in I \alpha\} \\
& \mathrm{I}_{\mathrm{b}}=\{\mu * b(\mathrm{Ib}) \in \mathrm{Ib}\} \\
& \mathrm{I}_{\mathrm{c}}=\{\mu \sigma(l c) \in I c\} \\
& \mathrm{CM}=\{\operatorname{Hm}(\mathrm{Gnd}) \mathrm{E} \mathrm{CH}\}
\end{aligned}
$$




\section{A. Fuzzy Inference System}

Fuzzy inference is the process of formulating the mapping from a given input to an output using fuzzy logic. The mapping then provides a basis from which decisions can be made, or patterns discerned. The process of fuzzy inference involves membership functions, fuzzy logic operators, and if-then rules. There are two types of fuzzy inference systems that can be implemented in the Fuzzy Logic Toolbox. They are Mamdani-type and Sugeno-type. In this setup Mamdani-type fuzzy inference system is used. The fuzzy inference system is shown in fig 2 .

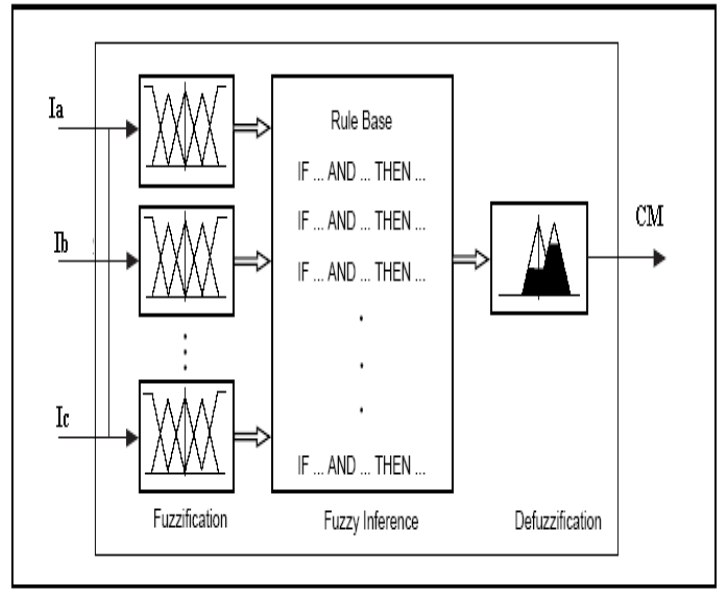

Fig .2 Internal Structure of Fuzzy Logic Controller

\section{B. Membership Functions}

A membership function (MF) is a curve that defines how each point in the input space is mapped to a membership value (or degree of membership) between 0 and 1.The input space is sometimes referred to as the universe of discourse. There are two types of membership functions. They are input membership function and output membership function.[6]

\section{1) Input Membership Function}

The input membership function consists of three input variables. They are $I_{a}, I_{b}$ and $I_{c}$ nothing but the stator current signals. Here trapezoidal and triangular membership function is used. The input variables are interpreted as linguistic variables, with Zero (Z), Small(S), Medium (M) and Big (B). The input membership function is shown in fig 3 . The range of input membership function varies from 0 to 3 .

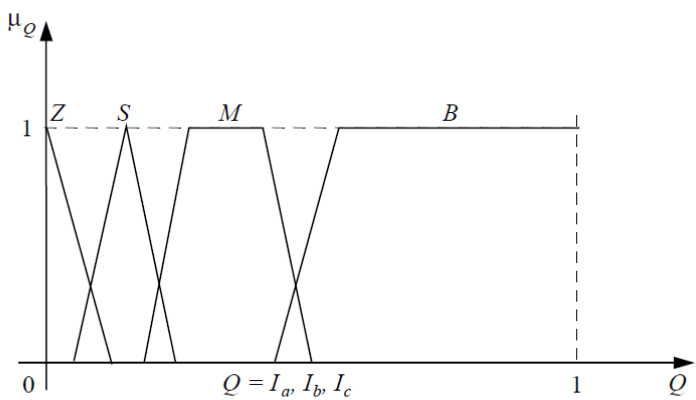

Fig .3 Fuzzy Membership functions for stator currents (Z: Zero, S: Small, M: Medium and B: Big)

2) Output Membership Function

The Output membership consists of one variable. The variable is the condition of the motor. The output variables are interpreted as linguistic variable with Good, Damaged and Seriously Damaged. Here also trapezoidal membership function is used. The output membership function is shown in fig 4. The range of output membership function varies from 0 to 100 .

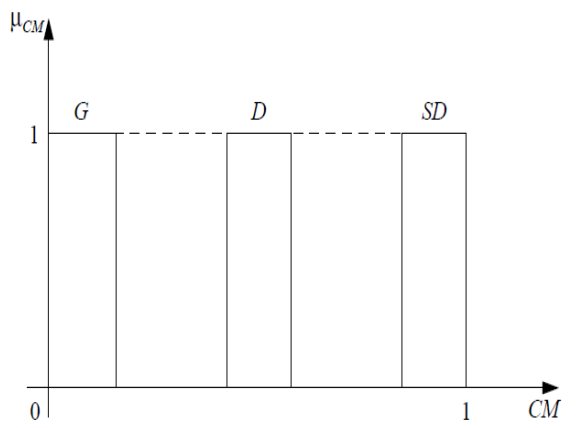

Fig .4 Fuzzy membership functions for the stator condition (G: Good, D: Damaged and SD: Seriously Damaged)

\section{3) Defuzzification and Fuzzy Rules}

Defuzzification is defined as the conversion of fuzzy output to crisp output. There are many types of defuzzification methods available. Here we used Center of Area (COA) method for defuzzification. Despite its complexity it is more popularly used because, if the areas of two or more contributing rules overlap, the overlapping area is counted only once.[7]

Rule (1): If $I a$ is $Z$ Then $C M$ is $S D$

Rule (2): If $I b$ is $Z$ Then $C M$ is $S D$

Rule (3): If $I c$ is $Z$ Then $C M$ is $S D$

Rule (4): If $I a$ is $B$ Then $C M$ is $S D$

Rule (5): If $I b$ is $B$ Then $C M$ is $S D$

Rule (6): If $I c$ is $B$ Then $C M$ is $S D$

Rule (7): If $I a$ is $\mathrm{S}$ and $I b$ is $\mathrm{S}$ and $I c$ is $M$ Then $C M$ is $D$

Rule (8): If $I a$ is $S$ and $I b$ is $M$ and $I c$ is $M$ Then $C M$ is $D$

Rule (9): If $I a$ is $M$ and $I b$ is $S$ and $I c$ is $M$ Then $C M$ is $D$ Rule (10): If $I a$ is $M$ and $I b$ is $M$ and $I c$ is $M$ Then $C M$ is $G$ Rule (11): If $I a$ is $S$ and $I b$ is $S$ and $I c$ is $S$ Then $C M$ is $G$ Rule (12): If $I a$ is $S$ and $I b$ is $M$ and $I c$ is $S$ Then $C M$ is $D$ Rule (13): If $I a$ is $M$ and $I b$ is $S$ and $I c$ is $S$ Then $C M$ is $D$ Rule (14): If $I a$ is $M$ and $I b$ is $M$ and $I c$ is $S$ Then $C M$ is $D$.

\section{Modeling And Simulation Of Induction Motorfor FAUlt DeteCtion USING MATLAB/SIMULINK}

Modeling here refers to the process of analysis and synthesis to arrive at a suitable mathematical description that encompasses the relevant dynamic characteristics of the component, preferably in terms of parameters that can be easily determined in practice. In mathematical modeling, we try to establish functional relationships between entities that are important. A model supposedly imitates or reproduces certain essential characteristics or conditions of the actual often on a different scale. It can take on various forms: physical, as in scale-models and electrical analogs of mechanical systems; mental, as in heuristic or intuitive knowledge; and symbolic, as in mathematical, linguistical, graphical, and schematical representations. In this chapter, the three-phase induction motor model has been derived instead of two phase model ( $\mathrm{d}-\mathrm{q}$ representation), which is very commonly used. This is because the two-phase model is driven under balance operation. This model constrained the driven solution for any problem to balance operation, which 
severely limits the scope of many practical problems that may be studied. Also, it impairs the accuracy of these solutions since absolute balanced conditions rarely apply. Three-phase representation of all system components has been chosen so as to allow for unsymmetrical operation and to enhance the practical significance of the derived model. Such a representation is able to represent in accurate detail the many unsymmetrical phenomena encountered, which is not possible when using d-q modeling methods. So, in order to gain an understanding of problems that does not comply directly with balanced operating conditions and for which $\mathrm{d}-\mathrm{q}$ methods of analysis are inappropriate, three-phase representation becomes essential.[8]

\section{A. Induction Motor Performance Parameter Analysis For Stator Fault}

When induction machines are expressed in three-phase axes, many of the inductances are function of the rotor displacement and therefore functions of rotor speed and time as shown in the following

Stator Inductances: It is assumed that the air gap of the induction machine is uniform and the stator and rotor windings are sinusoidally distributed, all the stator self-inductances are identical.

$$
L_{A A}=L_{B B}=L_{C C}=L_{l s}+L_{m s}
$$

The mutual inductance between any two stator windings is the same due to symmetry

$$
\begin{aligned}
& L_{A B}=L_{B A}=-0.5 L_{m s} \\
& L_{B C}=L_{C B}=-0.5 L_{m s} \\
& L_{C A}=L_{A C}=-0.5 L_{m s}
\end{aligned}
$$

Rotor Inductances: In the same manner to that given for the stator, the rotor self-inductances and mutual inductances are:

$L_{a a}=L_{b b}=L_{c c}=L_{l r}+L_{m r}$

$L_{a b}=L_{b a}=-0.5 L_{m r}$

$L_{b c}=L_{c b}=-0.5 L_{m r}$

$L_{c a}=L_{a c}=-0.5 L_{m r}$

$L_{A a}=L_{B b}=L_{C c}=L_{m s r} \cos \theta_{r}$

$L_{A c}=L_{B a}=L_{C b}=L_{m s r} \cos \left(\theta_{r}-120^{\circ}\right)$

$L_{A b}=L_{B c}=L_{C a}=L_{m s r} \cos \left(\theta_{r}+120^{\circ}\right)$

The mutual inductance between a stator winding and any rotor winding varies sinusoidally with rotor position. The figure 5. Shows the two dimensional diagram of three-phase induction motor with stator and rotor windings. [9]

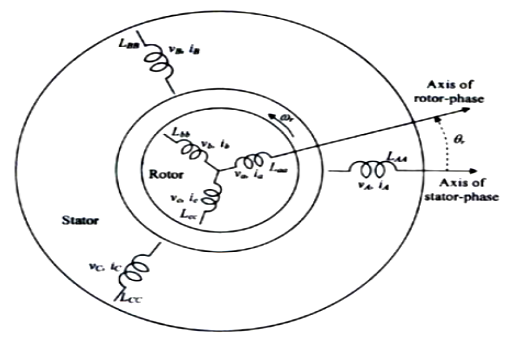

Fig .5 Three Phase Induction Motor

The voltage equations for a three-phase induction machine can be expressed as:
Stator Equation is

$$
\begin{gathered}
V_{A}=R_{A} i_{A}+\frac{d \lambda_{A}}{d t} \\
V_{B}=R_{B} i_{B}+\frac{d \lambda_{B}}{d t} \\
V_{C}=R_{C} i_{C}+\frac{d \lambda_{C}}{d t}
\end{gathered}
$$

Rotor equation is

$$
\begin{aligned}
& V_{a}=R_{a} i_{a}+\frac{d \lambda_{a}}{d t} \\
& V_{b}=R_{b} i_{b}+\frac{d \lambda_{b}}{d t} \\
& V_{c}=R_{c} i_{c}+\frac{d \lambda_{c}}{d t}
\end{aligned}
$$

\section{B. Simulink Diagram of Fuzzy Logic on an Induction Motor}

In this section, the implementation of the stationary reference abc model of a three phase induction motor using simulink, using the equations listed in the previous section has been given. Figure 6.shows an overall diagram of the induction motor in the stationary three-phase reference frame. The details of the subsystems in the main blocks are given in figure 7 .

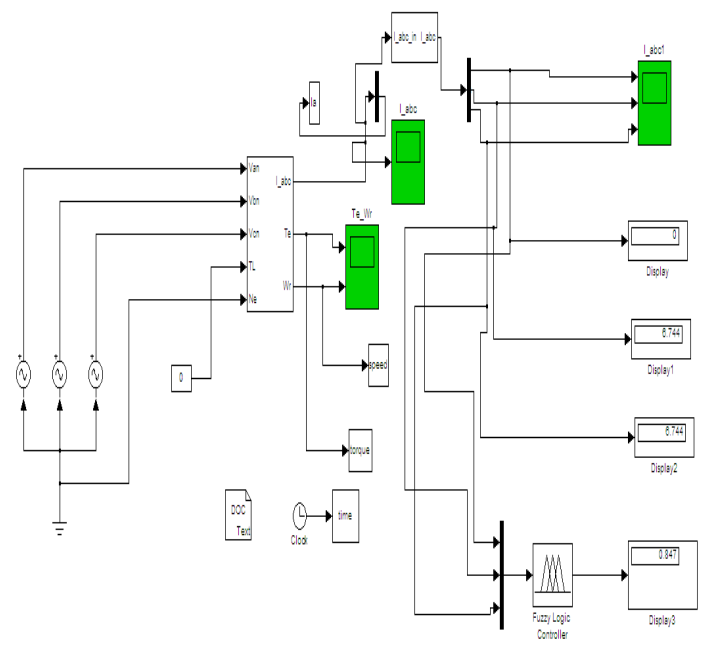

Fig. .6 Simulink Model of Condition Monitoring System

The parameters inside the induction motor three-phase model and the three phase source can be set by executing a $\mathrm{m}$-file which stores the all parameters used in the model. By running the $m$-file all the values of the parameters can be accessed by the model from the workspace. [10]

Machine Parameters: The parameters of the machine used for simulation are listed below:
Rated Voltage
Frequency
$\mathrm{V}=380 \mathrm{~V}$,
Stator Resistance
$\mathrm{f}=50 \mathrm{~Hz}$
Rotor Resistance
$\mathrm{R}_{\text {stator }}=15.3 \Omega$,
$\mathrm{R}_{\text {rotor }}=7.46 \Omega$,

The stator and rotor self-inductances are equal to

$\mathrm{L}_{\text {stator }}=\mathrm{L}_{\text {rotor }}=\mathrm{L}_{\text {leakage }}+\mathrm{L}_{\text {mutual }}=.035+.55=0.585 \mathrm{H}$,

The mutual inductance between any two stator and any tow rotor windings is equal to 
$\mathrm{L}_{\mathrm{ss}, \text { mutual }}=\mathrm{L}_{\mathrm{rr} \text {, mutual }}=-0.5 \mathrm{~L}_{\text {mutual }}=-0.275 \mathrm{H}$,

The mutual inductance between a stator winding and any rotor winding is equal to $\mathrm{L}_{\mathrm{sr} \text {, mutual }}=\mathrm{L}_{\text {mutual }}=0.55 \mathrm{H}$,

Number of Poles $\quad \mathrm{P}=4$,

Inertial constant $\quad \mathrm{J}=0.023 \mathrm{~kg} \cdot \mathrm{m}^{2}$

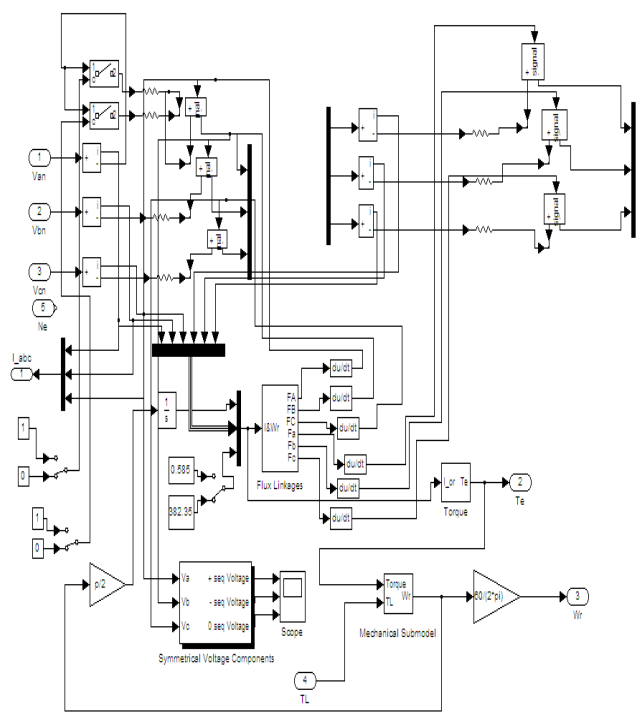

Fig. 7. Simulink Model of Induction Motor Subsystem

\section{Sub Models and Equations Governing the Subsystem of} Induction Motor

\section{1) Mechanical Model}

The dynamic load equation is:

$$
T_{e}-T_{L}=J \frac{d \omega_{r}}{d t}+D \omega_{r}
$$

$$
\begin{aligned}
\frac{d \omega_{r}}{d t}= & \frac{T_{e}-T_{L}}{J} \\
& \omega_{r}=\frac{1}{. J} \int\left(T_{e}-T_{L}\right) d t
\end{aligned}
$$

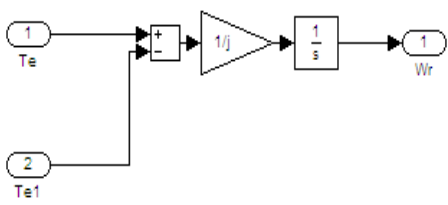

Fig .8 Simulink Mechanical Sub model

\section{2) Torque Model}

The electromechanical torque equation is:

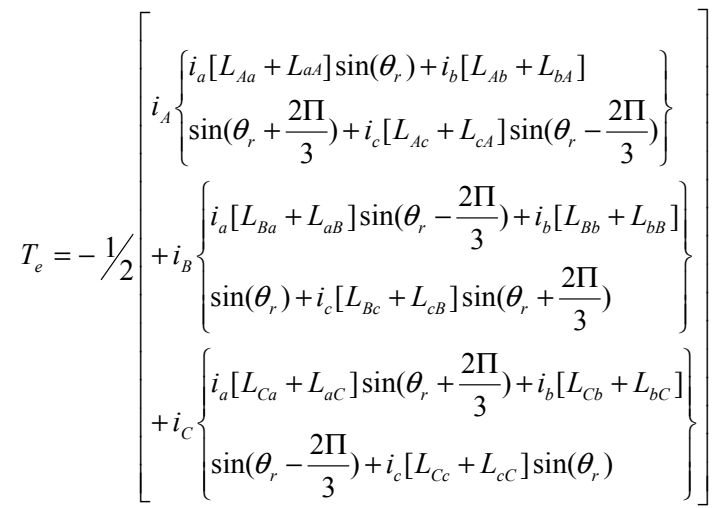

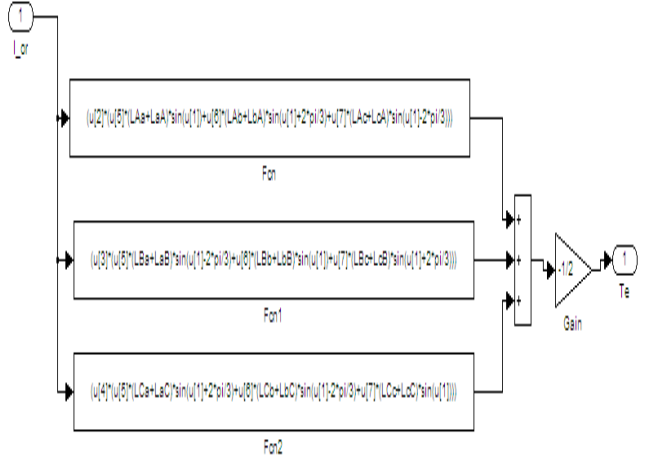

Fig .9 Simulink Torque Sub model

\section{3) Flux Linkages Model}

The flux linkages associated with the interactions between stator and rotor windings are represented by:

Stator:

$$
\begin{aligned}
& \lambda_{A}=L_{A A} i_{A}+L_{A B} i_{B}+L_{A C} i_{C}+L_{A a} \cos \left(\theta_{r}\right) i_{a}+L_{A b} \cos \left(\theta_{r}+\frac{2 \Pi}{3}\right) i_{b}+L_{A c} \cos \left(\theta_{r}-\frac{2 \Pi}{3}\right) i_{c} \\
& \lambda_{B}=L_{B A} i_{A}+L_{B B} i_{B}+L_{B C} i_{C}+L_{B a} \cos \left(\theta_{r}-\frac{2 \Pi}{3}\right) i_{a}+L_{B b} \cos \left(\theta_{r}\right) i_{b}+L_{B c} \cos \left(\theta_{r}+\frac{2 \Pi}{3}\right) i_{c} \\
& \left.\left.\left.\lambda_{C}=L_{C A} i_{A}+L_{C B} i_{B}+L_{C} i_{C}+L_{C a} \cos \theta_{r}+\frac{2 \Pi}{3}\right) i_{a}+L_{C b} \cos \theta_{r}-\frac{2 \Pi}{3}\right) i_{b}+L_{C c} \cos \theta_{r}\right) i_{c}
\end{aligned}
$$

Rotor:

$$
\begin{aligned}
& \lambda_{a}=L_{a A} \cos \left(\theta_{r}\right) i_{A}+L_{a B} \cos \left(\theta_{r}+\frac{2 \Pi}{3}\right) i_{B}+L_{a C} \cos \left(\theta_{r}-\frac{2 \Pi}{3}\right) i_{c}+L_{A a} i_{a}+L_{A b} i_{b}+L_{A c} i_{c} \\
& \lambda_{b}=L_{b A} \cos \left(\theta_{r}+\frac{2 \Pi}{3}\right) i_{A}+L_{a B} \cos \left(\theta_{r}\right) i_{B}+L_{a C} \cos \left(\theta_{r}-\frac{2 \Pi}{3}\right) i_{C}+L_{b a} i_{a}+L_{b b} i_{b}+L_{b c} i_{c} \\
& \left.\left.\left.\lambda_{c}=L_{b A} \cos \theta_{r}-\frac{2 \Pi}{3}\right) i_{A}+L_{c B} \cos \theta_{r}+\frac{2 \Pi}{3}\right) i_{B}+L_{c C} \cos \theta_{r}\right) i_{C}+L_{c a} i_{a}+L_{c b} i_{b}+L_{c c} i_{c}
\end{aligned}
$$

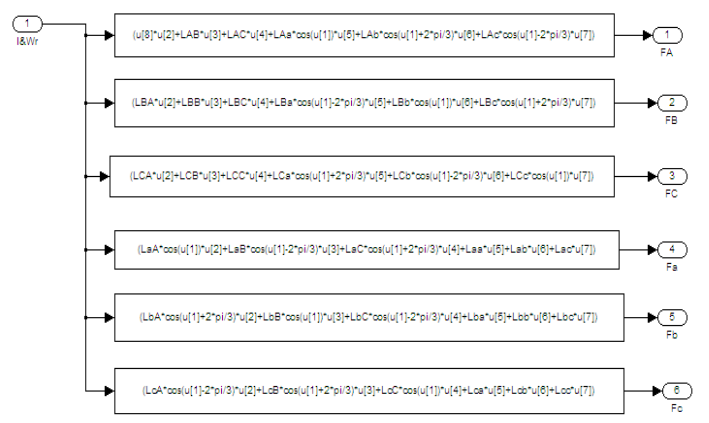

Fig .10 Simulink Sub model of Flux linkages

\section{4) Symmetrical Component Analysis}

The occurrence of shorted turns and phase imbalanced in the stator winding of induction motors cause predictable harmonics to appear in the spectrum of line currents and in the axial leakage flux. These changes however, can be small relative to the fundamental. The situation is further complicated because the induced harmonic components can exhibit beating at slip frequency or at a low integer multiple of slip frequency. This means that the detection of changes in the amplitude of such components can be unreliable, since it both frequency and time dependant. To overcome these drawbacks, the symmetrical component theory, and the approach is quite general, allowing for any asymmetrical arrangement of stator winding faults. By analyzing the relation of the positive and negative-sequence currents to that 
of torque and slip, when the machine is subjected to various operating conditions, the faults can be diagnosed. [11]

An unbalanced system of related phasors can be resolved into $\mathrm{n}$ systems of balanced phasors called the symmetrical components of the original phasors. In symmetrically wound machines there is no reaction between the different sequence quantities, if balanced voltages are applied to the stator, only balanced currents of the same sequence will flow. Due to the mutual winding coupling and other effects, the impedance displayed by machines will be different when exited by different sequence sources. The per phase impedance of the positive-sequence network will be different from those of negative and zero-sequence networks.

The expression for the three unbalanced phasors as a functionof the balanced phasor components. Fig 11 Shows the Simulink sub model of Symmetrical Components.

$$
\begin{aligned}
& v_{A}=v_{A 0}+v_{A 1}+v_{A 2} \\
& v_{B}=v_{B 0}+v_{B 1}+v_{B 2} \\
& v_{C}=v_{C 0}+v_{C 1}+v_{C 2}
\end{aligned}
$$

The positive, negative, and zero sequence vector components of any phase always have the angular relationship with respect to one another.[12]

$$
\begin{gathered}
\mathrm{V}_{\mathrm{A} 0}=\left(\mathrm{V}_{\mathrm{A}}+\mathrm{V}_{\mathrm{B}}+\mathrm{V}_{\mathrm{c}}\right) \\
\mathrm{V}_{\mathrm{A} 1}=\left(\mathrm{V}_{\mathrm{A}}+a \mathrm{~V}_{\mathrm{B}}+a^{2} \mathrm{~V}_{\mathrm{c}}\right) / 3 \\
\mathrm{~V}_{\mathrm{A} 2}=\left(\begin{array}{l}
\left.V_{a 0}+a^{2} \mathrm{~V}_{\mathrm{B}}+a \mathrm{~V}_{\mathrm{c}}\right) / 3 \\
V_{a 1} \\
V_{a 2}
\end{array}\right)=\frac{1}{3}\left(\begin{array}{ccc}
1 & 1 & 1 \\
1 & a & a^{2} \\
1 & a^{2} & a
\end{array}\right)\left(\begin{array}{l}
V_{a} \\
V_{b} \\
V_{c}
\end{array}\right) \\
\mathrm{a}=\exp (2 \pi / 3)
\end{gathered}
$$

If suppose $\mathrm{C}$ phase is lost and the motor is running at a steady speed. Then $\mathrm{V}_{\mathrm{a}}$ and $\mathrm{V}_{\mathrm{b}}$ are the remaining voltages and they produce equal and opposite line currents $\mathrm{I}_{\mathrm{a}}$ and $\mathrm{I}_{\mathrm{b}}$, which increase to around 1.73 to 2.00 times that of the normal. The back EMF generated in the machine armature will be approximately balanced in all three phases, since both the motor stator windings and rotor cage have distributed conductors. By ignoring stator resistance, the internal voltage $V_{m a}$ and $V_{m b}$ of phase $A$ and $B$ respectively will add vector ally with the respective stator leakage reactance voltage drops $\mathrm{V}_{\mathrm{sa}}$ and $\mathrm{V}_{\mathrm{sb}}$ to equal the applied voltages $\mathrm{V}_{\mathrm{a}}$ and $\mathrm{V}_{\mathrm{b}}$. For ungrounded neutral, zero-sequence current is neglected. The negative-sequence voltages produce currents which are limited by impedance that closely approximate those that apply when the motor is started. This negative-sequence current results in the production of counter torque. To compensate negative torque produced the positive-sequence current increases. The motor slip increases to allow the additional positive torque to develop. [13]

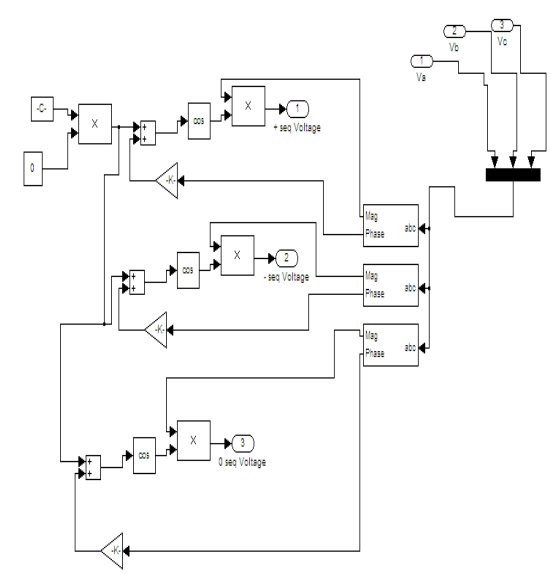

Fig .11 Simulink sub model of Symmetrical Components

\section{RESUlts AND DiscusSION}

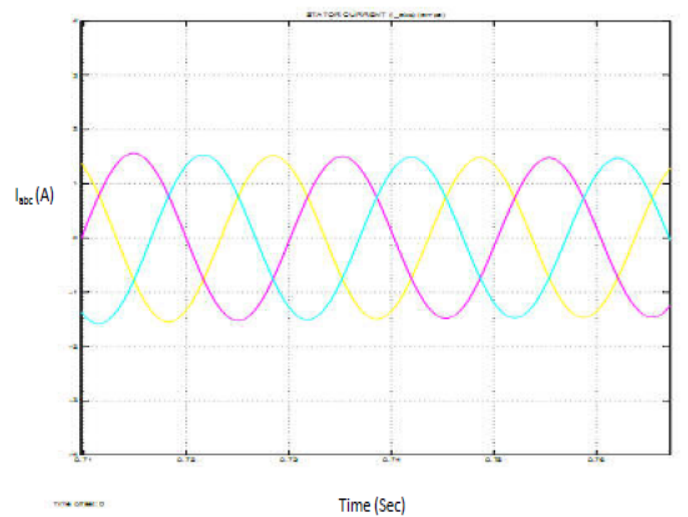

Fig .12 Three-phase Stator currents of Induction motor (Normal Operation)

\section{A. Normal Operation}

For the values given in above and using a simulation stop time of 2.0 seconds, the motor was simulated during starting from rest with rated voltage applied and no mechanical load. Figure 12 shows the Stator current and health of induction motor, Stator input voltage, speed and torque, symmetrical components of stator current, symmetrical components of stator induced voltage, symmetrical components of stator input voltage are shown. From these results it can be concluded that after the transient period is over, the health of the motor is good, and there is no negative sequence component in both stator induced voltage and stator current.[14]

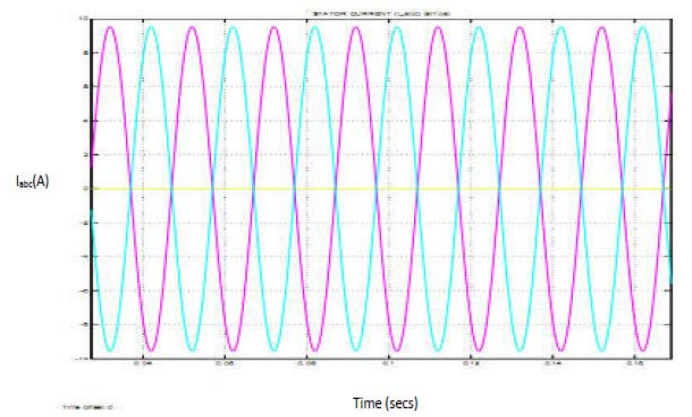

Fig .13 Three-phase Stator currents of Induction motor (Open Phase Fault Condition)

In this case after normal startup, at 0.5 second, $\mathrm{R}$ phase was open circuited and the corresponding results are shown in figures 13 . 


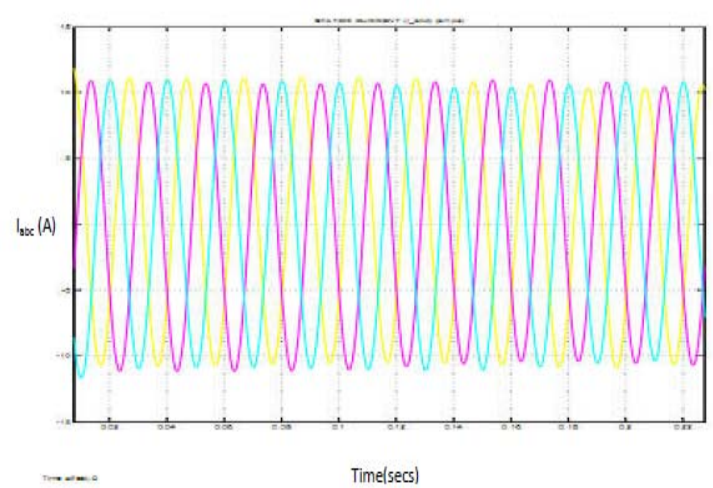

Fig .14 Three-phase Stator current of Induction motor (Turn-turn Fault Condition)

\section{B. Turn-Turn short in one phase winding}

After the simulation for normal operation of the induction motor model, simulation for the short circuit in the part of the winding in $\mathrm{R}$ phase has been carried out. At this condition the value of the stator resistance at short circuit fault is equal to $\mathrm{R}_{\text {stator, fault }}=13.1 \Omega$, we can find the value of the inductance at the fault state by using the ratio between the value of the resistance at both state (normal and fault). Thus the value of the inductance is

$$
\begin{gathered}
\frac{R_{\text {Stator }, \text { normal }}}{R_{\text {Stator }, \text { fault }}}=n=\frac{L_{\text {Stator }, \text { normal }}}{L_{\text {Stator }} \text {,fault }} \\
\frac{15.3}{13.1}=\frac{0.585}{L_{\text {Stator , fault }}} \Rightarrow \therefore L_{\text {Stator, fault }} \approx 0.5 \mathrm{H}
\end{gathered}
$$

Replacing the values of the stator resistance and stator self-inductance in phase $\mathrm{R}$ by these values the results can be obtained. Figure 14 shows the Stator current and health of induction motor, speed and torque, symmetrical components of stator current, symmetrical components of stator induced voltage, are shown. The simulation is started up with normal state parameters. After obtaining steady state at 0.5 second the turn fault has been created by changing the above said parameters. From these results it can be concluded that during normal operation (before fault), the health of the motor is Good, and there is no negative sequence component in both stator induced voltage and stator current. As soon as the fault is created the stator current becomes unbalanced, and the health of the induction motor goes seriously damaged and finally settles to Damaged state, and we can notice that there is presence of negative sequence component in both stator induced voltage and stator current waveforms during fault conditions.

\section{CONCLUSIONS}

A method of using fuzzy logic to interpret current sensors signal of induction motor for its stator condition monitoring was presented. Correctly processing theses current signals and inputting them to a fuzzy decision system achieved high diagnosis accuracy. There is most likely still room for improvement by using an intelligent means of optimization.

\section{ACKNOWLEDGMENT}

The authors are grateful to the management of Karunya University (Karunya Institute of Technology \& Sciences) Coimbatore, India for their support and encouragement.

\section{REFERENCES}

[1] Arfat siddique, member, ieee, g. S. Yadava, and bhim singh, senior member, ieee "'a review of stator fault monitoring techniques of induction motors", ieee transactions on energy conversion, vol. 20, no. 1 , march 2005 .

[2] Luís alberto pereira, daniel da silva gazzana, luís f. A. Pereira, "motor current signature analysis and fuzzy logic applied to the diagnosis of short-circuit faults in induction motors", 0-7803-9252-3/05/\$20.00 (C)2005 ieee.

[3] Neelam Mehala, Ratna Dahiya, "Condition monitoring methods, failure identification and analysis for Induction machines", International Journal of Circuits, Systems And Signal Processing, Issue 1, Vol 3, 2009.

[4] Benbouzid M. E. H., "A Simple Fuzzy Logic Approach for induction Motor Stator Condition Monitoring," IEMDC 2001. IEEE International, January 2001, pp. 634-639.

[5] Jarmo Ilonen, Joni-Kristian Kamarainen, Member, IEEE, Tuomo Lindh, Jero Ahola, Heikki Kälviäinen, Member, IEEE, and Jarmo Partanen, Member, IEEE," Diagnosis Tool for Motor Condition Monitoring “, IEEE Transactions on Industry Applications”, VOL. 41, NO. 4, JULY/AUGUST 2005

[6] Nyein Nyein Soe, Thet Thet Han Yee, and Soe Sandar Aung," Dynamic Modeling and Simulation of Three-phase Small Power Induction Motor", World .Academy of Science, Engineering and Technology 42,2008 .

[7] M. Arkan , D. Kostic-Perovic , P.J. Unsworth ," Modelling and simulation of induction motors with inter-turn faults for diagnostics", Electric Power Systems Research 75 (2005) 57-66.

[8] Peter Vas, Professor in Electrical Engineering, Department of Engineering, University of Aberdeen, "Parameter Estimation,Condition Monitoring,and Diagnosis of Electrical Machines".

[9] K. L . Shi, T . F. Chan, Y. K. Wong and S. L . ho," Modelling and Simulation of the three phase induction motor Using Simulink", Int. J. Elect. Enging. Educ., Vol. 36, pp. 163-172. Manchester U.P., 1999. Printed in Great Britain.

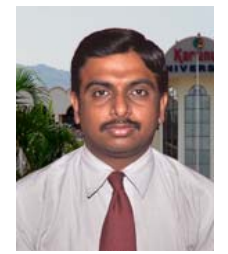

K.Vinoth Kumar received his B.E. Degree in Electrical and Electronics Engineering from Anna University, Chennai, Tamilnadu India in 2006. He obtained M.Tech, in Power Electronics and Drives from VIT University Vellore, Tamilnadu, India in 2008. Presently he is working with the Karunya Institute of Technology and Sciences (Karunya University) Coimbatore Tamilnadu, India working in the School of Electrical Science. He is pursuing Ph.D degree in Karunya University, Coimbatore India from 2009. He is present research interests are Condition Monitoring of Industrial Drives, Neural Networks and Fuzzy Logic, Special machines, Application of Soft computing Technique. He has published papers in International journals and conference and also four textbooks like Power Electronics, Neural Networks and Fuzzy Systems, Soft Computing and Basic Electrical Engineering. He is a member in IEEE (USA), MISTE and also in International association of Electrical Engineers (IAENG).

Dr.S.Suresh Kumar received his B.E. Degree in Electrical and Electronics Engineering from Bharathiar University Coimbatore, Tamilnadu India in 1992. He obtained M.E.from Bharathiar University Coimbatore, Tamilnadu India in 1997. He received is doctoral degree from Bharathiar University Coimbatore, Tamil nadu India in 2007. Presently he is working as a Head of the department and also Director for school of electrical sciences, in Karunya Institute of Technology and Sciences (Karunya University) Coimbatore Tamilnadu, India. He is having 17 years of teaching experience from PSG College of technology. His present research interests are Electrical Machines, Power Quality. He has published papers in International journals and conference. He is a member in IEEE (USA), ASE, ISCA, MCSI, and MISTE and also in International association of Electrical Engineers.

Badugu Praveena is from Pithapuram, in Andhra Pradesh and was born on February 10 in the year 1987. Completed her B.Tech in the year 2008 from Pragati Engineering College,P eddapuram,Andhra Pradesh. Doing her final semester of PG in Power Electronics and Drives Specialization, Karunya University. She is presently working as a Teaching Research Assistant in the same University. 